\title{
What is unique about the new Canadian COPD guidelines?
}

\author{
Denis E O'Donnell MD FRCPI FRCPC
}

$\mathrm{T}$ he prospect of digesting yet another set of 'best practice' guidelines is not an appealing one for the overwrought family physician. The Canadian Thoracic Society (CTS) panel, charged with the enormous task of developing new evidencebased recommendations, was acutely aware of this. Nevertheless, they were convinced that the time was right to tackle this important educational initiative, and somehow managed to summon considerable reserves of energy and enthusiasm to produce an excellent, state-of-the-art compendium on the optimal management of this condition (1). Faced with the evidence that death rates from chronic obstructive pulmonary disease (COPD) continue to escalate in Canada and that its prevalence has risen to unprecedented levels (particularly in older women), the panel believed that there was an urgent need to raise awareness of this disease, and to optimize diagnosis and management (2).

The skeptic may question the need for new national COPD guidelines when a recent authoritative, global consensus document on COPD management (Global Initiative for Chronic Obstructive Lung Disease [GOLD]) is already available (3). The panel believed that local guidelines that address the local needs of patients and health care providers, and that do so within the context of available resources, are preferable to more general international guidelines. Local experts are in the best position to identify local deficiencies in patient care that can be targeted for improvement. The development and effective implementation of new national guidelines requires broadbased collaboration among all of the key health care providers involved in the day-to-day care of COPD patients. In this regard, the Canadian guidelines are unique in that they were developed in close collaboration with numerous nonphysician experts in the management of COPD.

While the GOLD guidelines are in many ways exemplary, the CTS panel believed it could improve on some aspects of the document. For example, they suggested refinements to the following: definition of COPD; spirometric criteria for diagnosis; stratification of disease severity; and spirometry-linked management paradigms. These refinements and the rationale behind them are briefly reviewed below.

The Canadian guidelines emphasized the need to develop new chronic care models of management for COPD to replace the existing 'reactive' acute care models, which are less effective and more expensive. The pivotal role of structured patient education and, particularly, of self-management plans are highlighted to a much greater extent in our national guidelines than in the GOLD guidelines or other such documents. There is also a greater focus on the optimal integrated nonpharmacological management of patients with advanced symptomatic disease. Moreover, the CTS panel is among the first to courageously tackle the muchneglected issue of how to improve end-of-life care in COPD.

\section{Definition of COPD}

The GOLD definition of COPD emphasizes its pathophysiological underpinnings, namely airway inflammation and expiratory flow limitation (3). Because no effective COPD-specific, antiinflammatory therapy currently exists, and because expiratory flow limitation (a complex physiological concept) usually persists despite successful bronchodilation, the GOLD definition, although accurate, has negative connotations. The CTS clinical definition states that the airflow obstruction in COPD is partially reversible. Moreover, it reminds the reader that COPD, in its later stages, becomes a complex, multisystem disorder - the implication being that optimal management requires more than simple pharmacotherapy.

"COPD is a respiratory disorder largely caused by smoking that is characterized by progressive, partially reversible airway obstruction, systemic manifestations and increasing frequency and severity of exacerbations." (CTS) (1)

\section{Targeted spirometry for early diagnosis}

Despite numerous educational initiatives in the past, the early diagnosis of COPD remains an elusive goal in Canada. For a variety of reasons, the majority of family physicians have not embraced office spirometry, and many patients remain undiagnosed until the disease is advanced. To encourage early diagnosis, the CTS panel has recommended targeted screening of high risk patients rather than a more general screening of all smokers. Thus, smokers over 40 years of age who have persistent respiratory symptoms (eg, exertional breathlessness, cough and sputum, and recurrent respiratory infections) should be offered spirometry either in the office or at a specialized centre (1).

\section{Spirometric criteria for diagnosis}

There is no gold standard for the diagnosis of COPD: spirometric thresholds for clinically significant airway obstruction are, therefore, necessarily arbitrary. Nevertheless, a clinical diagnosis of COPD can reasonably be made if significant airway obstruction persists, despite acute short-acting bronchodilator therapy, in a patient who smokes and who has developed typical respiratory symptoms (see above). The GOLD diagnostic criteria are a postbronchodilator forced expiratory volume in $1 \mathrm{~s}\left(\mathrm{FEV}_{1}\right)$ less than $80 \%$ predicted or an 
$\mathrm{FEV}_{1} /$ forced vital capacity (FVC) ratio less than 0.7 . Because the $\mathrm{FEV}_{1} / \mathrm{FVC}$ ratio normally declines with age to values that are less than 0.7, even in nonsmokers, the GOLD criteria can lead to overdiagnosis if strictly applied (4). Therefore, the CTS have suggested that, for the purpose of diagnosis, both an $\mathrm{FEV}_{1}$ less than $80 \%$ predicted and an $\mathrm{FEV}_{1} / \mathrm{FVC}$ ratio less than 0.7 must be present after acutely administered bronchodilator therapy in patients with a pertinent history.

\section{Stratifying disease severity}

Existing stratification systems of disease severity are based exclusively on the measurement of $\mathrm{FEV}_{1}(3,5)$. This approach has limitations in that $\mathrm{FEV}_{1}$ values correlate poorly with measures of morbidity such as dyspnea intensity, exercise intolerance and quality of life (6-8). Ideally, therefore, clinical assessments of severity should include an evaluation of dyspnea and disability, as well as the traditional objective measures of airway obstruction. For this reason, the CTS panel encourages caregivers to use the simple Medical Research Council (MRC) questionnaire to evaluate dyspnea and functional capacity in their patients (9). This easy-to-use tool has been validated for this purpose and has been shown to correlate with measures of quality of life and to predict mortality independent of $\mathrm{FEV}_{1}(8,10)$. The responsiveness of this MRC-based stratification system to therapeutic intervention (on an individual basis) remains to be established, but several studies have shown improvements in the MRC grade in the presence of minimal or no changes in $\mathrm{FEV}_{1}$ after various treatments.

\section{Individualized dyspnea- or disability-driven management paradigms}

Existing management paradigms for COPD are closely linked to $\mathrm{FEV}_{1}(3,5)$. While spirometry is required for diagnosis and follow-up of the disease, and as an objective measure of the severity of airway obstruction, it is not universally used to guide treatment choices or to evaluate treatment benefits. This is the case particularly among family physicians who may not have ready access to spirometry. The main purpose of bronchodilator therapy is for symptom relief, and treatment is escalated until maximal possible alleviation of dyspnea is achieved. The CTS panel recommends an individualized, stepwise increase in therapy based on the subjective response of the patient to pharmacotherapy. Thus, for patients with persistent exertional dyspnea (eg, MRC grade higher than 2), short-acting bronchodilators should be prescribed. If symptoms persist despite a need to use these agents more than twice per day, a long-acting bronchodilator should be commenced in conjunction with the short-acting bronchodilator. Further escalation of bronchodilator therapy (with combined long-acting bronchodilators) is often needed in more symptomatic patients (MRC grades 3 and 4). Patients with severe dyspnea and disability (MRC grades 4 and 5) need comprehensive management with additional nonpharmacological therapy to achieve optimal results.

\section{CTS pharmacotherapy recommendations: background and} rationale

The CTS panel adopted a novel and rigorous approach to the evaluation of scientific literature with respect to the efficacy of all therapeutic interventions in COPD (1). In the past, the primary outcome measure of interest has been almost exclusively
$\mathrm{FEV}_{1}$. The CTS panel provided a much more comprehensive evaluation of all current therapies and considered the evidence for a positive impact of each of these in the broader domains of impairment, disability and handicap. Arbitrary thresholds for a clinically meaningful improvement were set a priori for each of these parameters, and each intervention was evaluated accordingly. This sort of analysis quickly determined that long-acting bronchodilators were superior to short-acting bronchodilators in terms of their impact on quality of life (11-20). In turn, this led to the recommendation for an early introduction of these newer agents (long-acting beta-agonists [LABAs] or anticholinergics) for patients with persistent symptoms.

Most randomized, placebo-controlled clinical trials are designed to evaluate the efficacy of the test drug in relative isolation and often not in the context of the regularly prescribed, 'real life' medications. For example, in the large inhaled corticosteroid trials, it can be argued that bronchodilator therapy was not optimized before the introduction of the test medication (21-24). The lack of information on the added value of various medications over and above that of regular therapy makes it difficult to provide definitive recommendations. Therefore, the panel frequently had to resort to a 'best guess' consensus opinion based on the available, incomplete data. One of the most controversial recommendations in the document was the positioning of oral theophylline in the dyspneadriven pharmacotherapy paradigm. The side effect profile of this drug, the risk of negative drug interactions and the necessity to monitor blood levels have largely precluded routine use of this medication in Canada. However, there is good evidence that the addition of this oral drug to salmeterol therapy can improve symptom alleviation in patients with severe COPD (25). Hence, the consensus recommendation was that a trial of theophylline should be considered in patients with more advanced disease who remain breathless despite combined inhaled medications.

\section{The 'inflammatory' steroid debate}

The CTS panel believed that inhaled corticosteroid (ICS) therapy should be reserved for patients with more severe airway obstruction (eg, $\mathrm{FEV}_{1}$ less than $50 \%$ predicted) who suffer recurrent acute exacerbations of COPD (AECOPDs). This is based on the evidence that in this patient subset, regular, 'prophylactic' ICS therapy is associated with a clinically important reduction in the rate and severity of AECOPDs (21-24). The panel did not support the idea of an individualized trial of ICS therapy to identify potential responders proposed by the GOLD guidelines; the thresholds for clinically important postbronchodilator improvements in $\mathrm{FEV}_{1}$ and the ideal duration of such trials remain unknown. Moreover, conducting such trials on a regular basis present logistical problems for many Canadian family physicians.

Combined ICSs and LABAs have been shown to be superior to placebo in improving lung function, severity of exacerbations and health status in large population studies (25-28). However, the evidence that such combination therapy is superior to the LABA component alone (arguably, the main comparison of interest) with respect to the above-listed outcome variables is currently insufficient to make any definitive recommendation on its use for the improvement of dyspnea 
and disability. Nevertheless, in the absence of conclusive evidence, the panel suggested that ICS/LABA combination could be considered on an individual basis for patients with more severe airway obstruction who remain breathless in spite of reasonable bronchodilator therapy.

\section{AECOPDs: New definition and classification of severity}

Many disparate definitions of exacerbation are in common currency worldwide (29). The panel proposed a pragmatic definition that they hoped would be useful in clinical practice: "a sustained worsening of dyspnea, cough or sputum production leading to an increase in the use of maintenance medications and/or supplementation with additional medications" (1).

Consistent with other recent evidence-based guidelines, the CTS emphasized the importance of intensifying bronchodilator therapy and of prescribing a short course of oral corticosteroid therapy to suppress acute inflammation $(3,30)$. Sputum purulence was suggested as an important indication for antibiotic therapy. To guide appropriate antibiotic selection, the panel proposed a novel approach of dividing AECOPDs into simple and complicated classifications. These classifications are based on the presence of risk factors for treatment failure due to infection with more virulent or resistant microbial pathogens. Simple AECOPDs occur in patients with mild to moderate disease and are less likely to be caused by virulent or resistant pathogens. They generally respond well to bronchodilators, oral steroids and first-line antibiotics such as the aminopenicillins or the newer macrolides $(31,32)$. Complicated AECOPDs are associated with greater morbidity and mortality risks, and need prompt, aggressive treatment with steroids and bronchodilators. Complicated AECOPDs are more likely to occur in patients with more severe airway obstruction who suffer from frequent exacerbations and who have significant comorbidities. Gram-negative

\section{REFERENCES}

1. O'Donnell DE, Aaron S, Bourbeau J, et al. Canadian Thoracic Society recommendations for management of chronic obstructive pulmonary disease - 2003. Can Respir J 2003;10(Suppl A):11A-65A.

2. Centre for Chronic Disease Prevention and Control, Health Canada, Canadian Institute for Health Information. Editorial Board Respiratory Disease in Canada. Ottawa: Health Canada, 2003.

3. Pauwels RA, Buist AS, Calverley PM, Jenkins CR, Hurd SS. GOLD Scientific Committee. Global strategy for the diagnosis, management, and prevention of chronic obstructive pulmonary disease. NHLBI/WHO Global Initiative for Chronic Obstructive Lung Disease (GOLD) Workshop summary. Am J Respir Crit Care Med 2001;163:1256-76.

4. Hankinson JL, Odencrantz JR, Fedan KB. Spirometric reference values from a sample of the general US population. Am J Respir Crit Care Med 1999;159:179-87.

5. BTS guidelines for the management of chronic obstructive pulmonary disease. The COPD Guidelines Group of the Standards of Care Committee of the BTS. Thorax 1997;52(Suppl 5):S1-28.

6. O'Donnell DE, Revill S, Webb KA. Dynamic hyperinflation and exercise intolerance in COPD. Am J Respir Crit Care Med 2001;164:770-7.

7. Tantucci C, Duguet A, Similowski T, Zelter M, Derenne JP, Milic-Emili J. Effect of salbutamol on dynamic hyperinflation in chronic obstructive pulmonary disease patients. Eur Respir J 1998; $12: 799-804$.

8. Ferrer M, Alonso J, Morera J, et al. Chronic obstructive pulmonary disease and health-related quality of life. Ann Intern Med 1997;127:1072-9.

9. Fletcher CM, Elmes PC, Wood CH, Fairbain AS. The significance of respiratory symptoms and the diagnosis of chronic bronchitis in a working population. Br Med J 1959;5147:257-66. and beta-lactam-resistant pathogens are often implicated. These infections therefore require treatment with the newer fluroquinolones or beta-lactam/beta-lactamase inhibitors (31-33).

\section{The importance of comprehensive management plans}

The pivotal importance of the nonpharmacological management of COPD was highlighted in the Canadian guidelines to a greater extent than in any such previous document. This reflects the deeply held conviction of the panel (many of whom direct pulmonary rehabilitation programs) of the value of such interventions. There is now convincing evidence that self-management programs and supervised multidisciplinary rehabilitation programs consistently improve quality of life in patients with COPD, at least for the short term $(34,35)$. However, the sad reality is that only a minority of Canadian patients have access to such programs. Clearly, there is an urgent need to convince governments of the potential health benefits and cost-effectiveness of establishing supervised, home-based rehabilitation programs in communities across the nation. One positive development applauded by the CTS panel is the recent emergence of certified COPD educators in Canada. These individuals will undoubtedly play an important role in instituting effective continuing care for this neglected population.

The new Canadian COPD guidelines offer a fresh perspective on the modern day management of this common condition. The unique features described in this brief commentary are a credit to the numerous individuals who generously participated in the development process. The main message permeating the entire document is that COPD is a preventable and treatable disease. There is no longer any room for therapeutic nihilism: modern pharmacological and nonpharmacological treatments effectively improve health status, even in patients with severe disease.

10. Nishimura K, Izumi T, Tsukino M, Oga T. Dyspnea is a better predictor of 5-year survival than airway obstruction in patients with COPD. Chest 2002;121:1434-40.

11. Dahl R, Greefhorst LAPM, Nowak D, et al. Inhaled formoterol dry powder versus ipratropium bromide in chronic obstructive pulmonary disease. Am J Respir Crit Care Med 2001;164:778-84.

12. Ulrik CS. Efficacy of inhaled salmeterol in the management of smokers with chronic obstructive pulmonary disease: A single centre randomised, double blind, placebo controlled, crossover study. Thorax 1995;50:750-4.

13. Boyd G, Morice AH, Pounsford JC, Seibert M, Peslis N, Crawford C. An evaluation of salmeterol in the treatment of chronic obstructive pulmonary disease (COPD). Eur Respir J 1997;10:815-21.

14. Cazzola M, Matera MG, Santangelo G, Vinciguerra A, Rossi F, D'Amato G. Salmeterol and formoterol in partially reversible severe chronic obstructive pulmonary disease: A dose-response study. Respir Med 1995;89:357-62.

15. Grove A, Lipworth BJ, Ried P, et al. Effects of regular salmeterol on lung function and exercise capacity in patients with chronic obstructive airways disease. Thorax 1996;51:689-93.

16. Goldkorn A, Diotto P, Burgess C, et al. The pulmonary and extrapulmonary effects of high-dose formoterol in COPD: A comparison with salbutamol. Respirology 2004;9:102-8.

17. Casaburi R, Mahler DA, Jones PW, et al. A long-term evaluation of once-daily inhaled tiotropium in chronic obstructive pulmonary disease. Eur Respir J 2002;19:217-24.

18. Vincken W, van Noord JA, Greefhorst AP, et al. Dutch/Belgian Tiotropium Study Group. Improved health outcomes in patients with COPD during 1 yr's treatment with tiotropium. Eur Respir J 2002;19:209-16. 
19. O’Donnell DE, Magnussen H, Aguilaniu B, Gerken F, Hamilton A, Fluege T. Spiriva (Tiotropium) improves exercise tolerance in COPD. Eur Resp J. (In press)

20. Donohue JD, van Noord JA, Bateman ED, et al. A 6-month, placebo controlled study comparing lung function and health status changes in COPD patients treated with tiotropium or salmeterol. Chest 2002;122:47-55.

21. Pauwels RA, Lofdahl CG, Laitinen LA, et al, for the European Respiratory Society Study on Chronic Obstructive Pulmonary Disease. Long-term treatment with inhaled budesonide in persons with mild chronic obstructive pulmonary disease who continue smoking. N Engl J Med 1999;340:1948-53.

22. Vestbo J, Sorensen T, Lange P, Brix A, Torre P, Viskum K. Long-term effect of inhaled budesonide in mild and moderate chronic obstructive pulmonary disease: A randomized controlled trial. Lancet 1999;353:1819-23.

23. Lung Health Study Research Group. Effect of inhaled triamcinolone on the decline in pulmonary function in chronic obstructive pulmonary disease. N Engl J Med 2000;343:1902-9.

24. Burge PS, Calverley PM, Jones PW, Spencer S, Anderson JA, Maslen TK. Randomised, double blind, placebo controlled study of fluticasone propionate in patients with moderate to severe chronic obstructive pulmonary disease: The ISOLDE trial. BM] 2000;320:1297-303.

25. Zu Wallack RL, Mahler DA, Reilly D, et al. Salmeterol plus theophylline combination therapy in the treatment of COPD Chest 2001;119:1661-70.

26. Mahler DA, Wire P, Horstman D, et al. Effectiveness of fluticasone propionate and salmeterol combination delivered via the Diskus device in the treatment of chronic obstructive pulmonary disease. Am J Respir Crit Care Med 2002;166:1084-91.
27. Calverley P, Pauwels R, Vestbo J, et al. Combining salmeterol and fluticasone in the treatment of chronic obstructive pulmonary disease: A randomized controlled trial. Lancet 2003;361:449-56

28. Szafranski W, Cukier A, Ramirez A, et al. Efficacy and safety of budesonide/formoterol in the management of chronic obstructive pulmonary disease. Eur Respir J 2003;21:74-81.

29. Rodriguez-Roisin R. Toward a consensus definition for COPD exacerbations. Chest 2000;117(Suppl 2):398S-401S

30. Niewoehrier D, Erbland M, Deupree R, et al, for the Department of Veterans Affairs Cooperative Study Group. Effect of systemic glucocorticoids on exacerbations on chronic obstructive pulmonary disease. N Engl J Med 1999;340:1941-7.

31. Anthonisen NR, Manfreda J, Warren CP, Hershfield ES, Harding GK, Nelson NA. Antibiotic therapy in exacerbations of chronic obstructive pulmonary disease. Ann Intern Med 1987;106:196-204.

32. Wilson R, Schentag J, Ball P, Mandell L. A comparison of gemifloxacin and clarithromycin in acute exacerbations of chronic bronchitis and long-term clinical outcomes. Clin Ther 2002;24:639-52.

33. Chodosh S, Schreurs A, Siami G, et al, for the Bronchitis Study Group. Efficacy of oral ciprofloxacin vs clarithromycin for treatment of acute bacterial exacerbations of chronic bronchitis. Clin Infect Dis 1998;27:730-8.

34. Bourbeau J, Julien M, Maltais F, et al. Reduction of hospital utilization in patients with chronic obstructive pulmonary disease: A disease-specific self-management intervention. Arch Intern Med 2003; 163:585-91.

35. Lacasse Y, Brosseau L, Milne S, et al. Pulmonary rehabilitation for chronic obstructive pulmonary disease. Cochrane Database Syst Rev 2002;3:CD003793. 


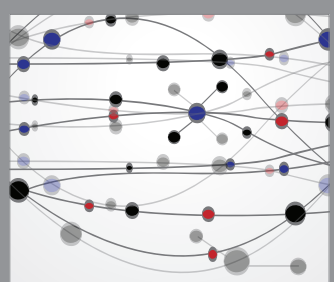

The Scientific World Journal
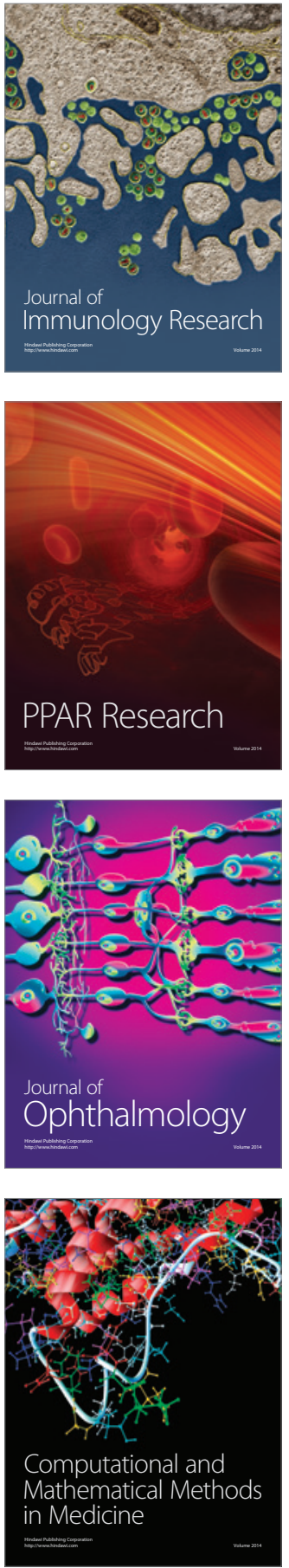

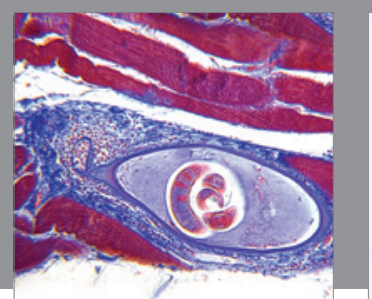

Gastroenterology Research and Practice

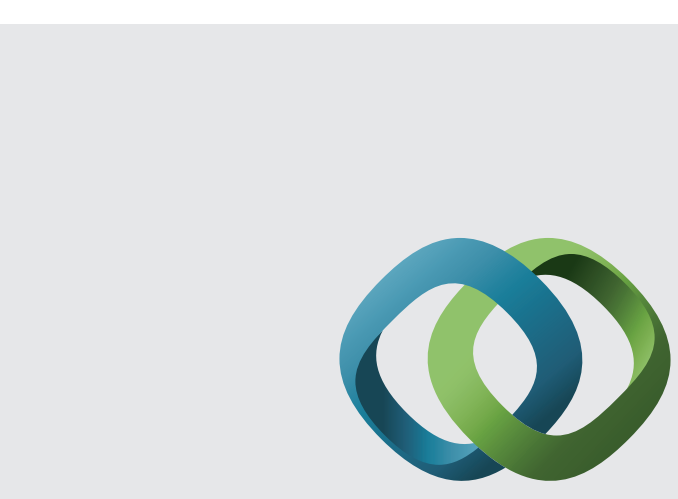

\section{Hindawi}

Submit your manuscripts at

http://www.hindawi.com
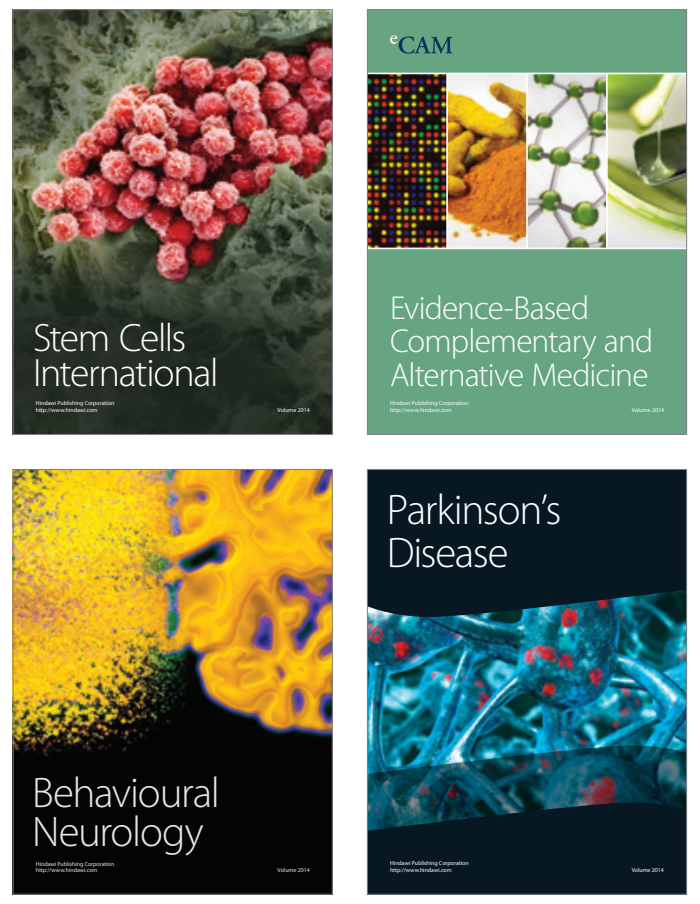
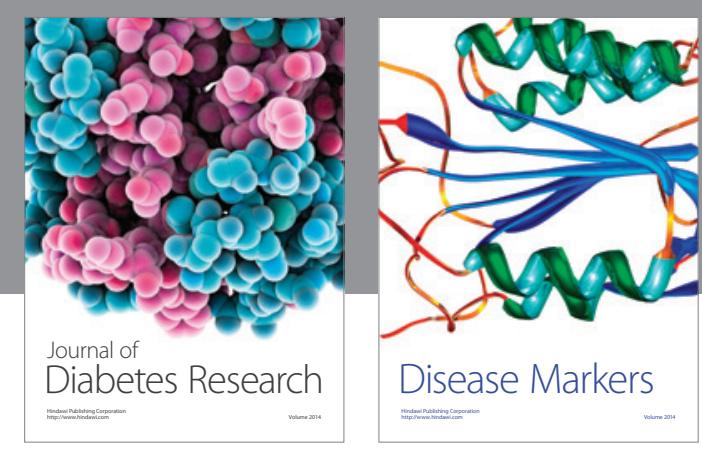

Disease Markers
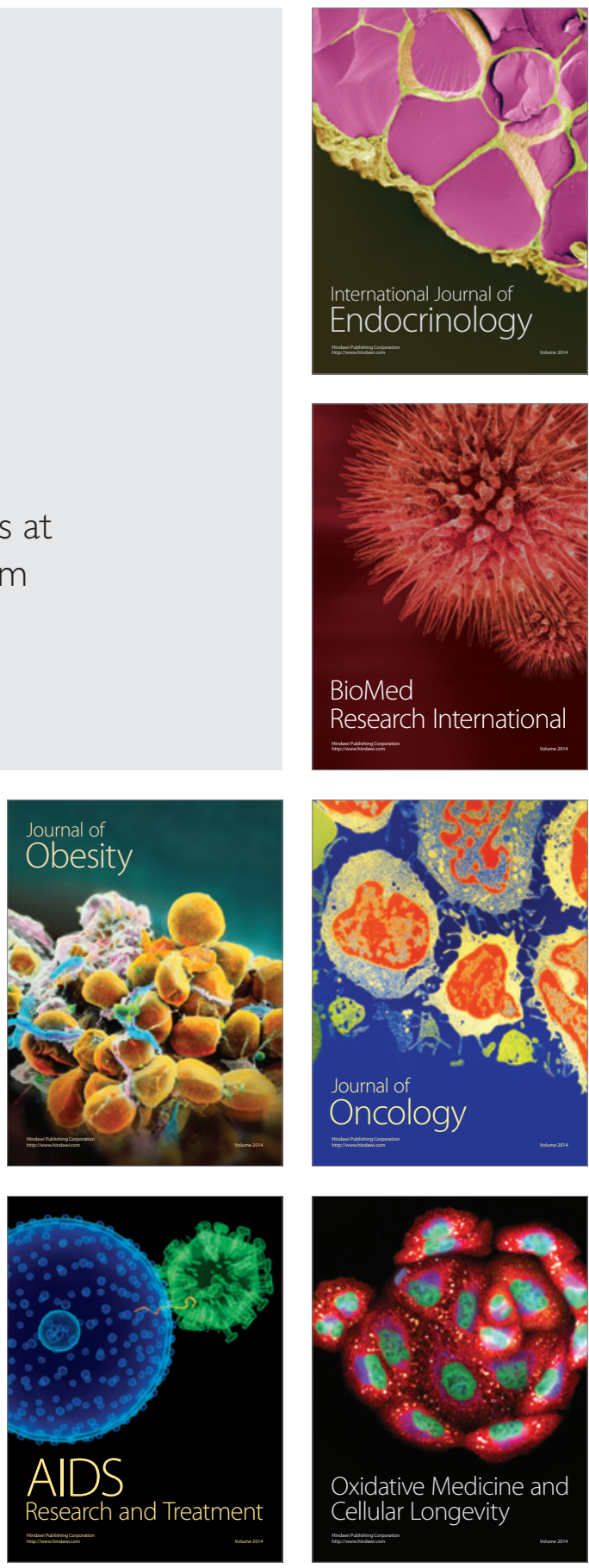